\title{
DETERMINATION OF SPECIFIC POWER PARAMETERS AND COEFFICIENT OF SLIPPING OF TRACTOR WHEEL
}

\author{
Alexander Pastukhov, Mikhail Romanchenko \\ Belgorod State Agricultural University named after V. Gorin, Russia \\ pastukhov_ag@mail.ru,mir-23@mail.ru
}

\begin{abstract}
The technique of determination of weight ratio longitudinal force, weight ratio traction moment, coefficient of slipping of the wheel and their analysis is given at variation of the central angle of the contact area of the tire. Longitudinal force consists of two components - on the site of slipping and on the site of rest of the contact area of the tire. The first component is defined by normal reaction of seating on the site of slipping and dynamic coefficient of traction of the tire, which is expressed by the function from relative normal reaction on the site of slipping and is in interval of two boundary values. The maximum and minimum values are equal according to the tire static friction coefficient without slipping of the wheel and to tire sliding friction coefficient at full slipping of the wheel. The second component is defined by normal reaction of seating on the site of rest and static coefficient of traction of the tire, which is expressed by the function from relative normal reaction on the site of rest and is limited to two limits - zero value and value of the coefficient of static friction of the tire. The traction moment on the wheel is defined by the work of longitudinal force on the radius of its rolling. The optimum value of the coefficient of slipping of the wheel is defined by functions of the weight ratio traction moment on the wheel to the maximum. Settlement assessment for the wheel with the Goodyear OPTITRAC DT812 tire of standard size 520/70R38 of the BELARUS 82.1 tractor is executed. The central angle of the contact area of the tire is equal to 0.881 radian. The maximum values of the weight ratio longitudinal force and the weight ratio traction moment are respectively to 0.722 and 0.634 . Coefficients of slipping of the wheel make at the same time respectively 0.15 and 0.107 . These values do not exceed the slipping coefficient size limited under operating conditions to values 0.18 and 0.15 for tractors according to one and two leading bridges.
\end{abstract}

Keywords: wheel, tire, force, moment, slipping, friction, traction.

\section{Introduction}

Operating speed of the movement and the realized tractive effort on driving wheels of the tractor have significant effect on the capacity of the engine and tractor unit at field and transport works [1;2]. The choice of rational loading of the tractor in these parameters is problematic as it is not possible to maximize them at the same time. Determination of effective indicators of driving wheels of the tractor in the traction mode proceeds from the need of achievement of the maximum traction moment, at restriction of the coefficient of slipping of wheels, which is quantitatively established for wheel tractors with one or two leading bridges, respectively, 0.18 and 0.15 allowed in field environment [1]. In this regard joint assessment of observance of these requirements, when choosing the rational traction mode of driving wheels of the tractor equipped, new, more perfect tires are of practical interest.

The object of the research - tractor wheel in the leading mode of rolling. The subject of the research - process of formation of longitudinal force and the traction moment on the driving wheel at partial slipping of the tire on seating.

The purpose of the research - optimization of specific power parameters and the coefficient of slipping of the driving wheel of the tractor.

For achievement of the goal it is necessary to solve the following problems:

1. to make an analytical model of interaction of the tractor wheel with seating in the leading mode of rolling;

2. to investigate dependence of the coefficient of traction on the site of slipping on relative normal reaction on the site of slipping of the contact area of the tire;

3. to investigate dependence of the coefficient of traction on the site of rest on relative normal reaction on the site of rest of the contact area of the tire;

4. to investigate dependence of the specific longitudinal force and the specific traction moment on the coefficient of slipping of the wheel at variation of the central angle of the contact area of the tire. 


\section{Materials and methods}

To study power parameters of interaction of the wheel with seating various methods based on the known analytical models [3-6] are applied. An important factor when using this or that model is the choice of the suitable law of distribution of specific normal reaction on the length of the contact area of the tire. Distribution can be presented in a diagram with rectangular, trapezoidal, elliptic or parabolic dependences [7-10]. Advantage of parabolic dependence is that it can be transformed properly according to the wheel load and geometrical form of the contact area of the tire. An important factor is also establishment of functional dependence of the coefficient of traction of the tire on the coefficient of slipping of the wheel on seating. Many scientific works are devoted to search of the most flexible functional dependences for various seatings, for example [3;7;11]. However, the known dependences are mainly empirical with a set of the constant and variable coefficients having restrictions. The most perfect is the specified analytical model of wheel rolling in the traction mode, which unites power and kinematic parameters of interaction of the wheel with seating [12;13]. In addition to this model is representation of resultant longitudinal force two components on sites of slipping and rest of the contact platform of the tire.The model assumes distribution of specific normal reaction on the length of the contact platform of the tire in parabolic form with a flat top. Use of parabolic dependence of the fourth degree is more acceptable that is characteristic of the contact platform of a low-pressure tire.

Traction torque $M_{t}, \mathrm{~N} \cdot \mathrm{m}$, on the driving wheel is defined by expression [13]

$$
M_{t}=R_{x} r_{k},
$$

or, taking into account formation of resultant tractive effort on sites of slipping and the rest of the contact area of the tire and dependences, with the subsequent transformation

$$
\begin{aligned}
& R_{x}=R_{x \text { slip }}+R_{x \text { rest }}, \\
& R_{x \text { slip }}=R_{z \text { slip }} \cdot \mu_{\text {trslip }}, \\
& R_{x \text { rest }}=R_{z \text { rest }} \cdot \mu_{\text {trrest }}, \\
& R_{z \text { slip }}=G_{\mathrm{k}} \cdot \delta_{R z \text { slip}}, \\
& R_{z \text { rest }}=G_{\mathrm{k}}-R_{z \text { slip }}, \\
& r_{k}=r_{k f}\left(1-\delta_{k}\right),
\end{aligned}
$$

from which, after integration of parabolic dependence of specific normal reaction on the site of slipping of the contact area of the tire, expression follows

$$
M_{t}=G_{k}\left\{\begin{array}{l}
\left(5 \delta_{\text {slip }}^{2}-10 \delta_{\text {slip }}^{3}+10 \delta_{\text {slip }}^{4}-4 \delta_{\text {slip }}^{5}\right) \mu_{\text {trlip }}+ \\
+\left[1-\left(5 \delta_{\text {slip }}^{2}-10 \delta_{\text {slip }}^{3}+10 \delta_{\text {slip }}^{4}-4 \delta_{\text {slip }}^{5}\right)\right] \mu_{\text {trrest }}
\end{array}\right\} r_{k f}\left(1-\delta_{k}\right),
$$

where $R_{x s l i p}$ - longitudinal jet force on the site of slipping of the contact area of the tire, N;

$R_{\text {xrest }}$ - longitudinal jet force on the site of rest of the contact area of the tire, N;

$R_{z s l i p}$ - normal reaction on the site of slipping of the contact area of the tire, N;

$R_{\text {zrest }}$ - normal reaction on the site of trest of the contact area of the tire, $\mathrm{N}$;

$\mu_{\text {trslip }}$ - dynamic coefficient of traction of the contact area of the tire on the site of slipping;

$\mu_{\text {trrest }}$ - static coefficient of clutch of the contact area of the tire on the site of rest;

$G_{k}$ - normal (vertical) load of the wheel of seating, N;

$\delta_{R z s l i p}$ - relative normal reaction on the site of slipping of the contact area of the tire;

$r_{k}$ - rolling radius of the wheel in the traction mode, $\mathrm{m}$;

$r_{k f}$ - rolling radius of the wheel in the free mode, m;

$\delta_{\text {slip }}$ - coefficient of slipping of the contact area of the tire;

$\delta_{k}-$ coefficient of slipping of the wheel.

Coefficient of slipping of the contact platform of the tire $\delta_{\text {slip }}$ is defined by the relation of the length of the site of slipping of the contact area to all its length 


$$
\delta_{\text {slip }}=l_{\text {slipca }} / l_{c a},
$$

where $l_{\text {slipca }}-$ length of the site of slipping of the contact area of the tire, m;

$l_{\mathrm{ca}}-$ length of the contact platform of the tire, $\mathrm{m}$.

The site of slipping is in the rear of the contact area of the tire and at full slipping extends to the front part of the contact area to all its length, and normal reaction on the site of slipping of the contact area of the tire makes [10]:

$$
R_{z s l i p}=G_{k}\left(5 \delta_{s l i p}^{2}-10 \delta_{\text {slip }}^{3}+10 \delta_{\text {slip }}^{4}-4 \delta_{\text {slip }}^{5}\right) .
$$

Dynamic coefficient $\mu_{t r}$ slip traction of the contact area of the tire on the site of slipping is determined by the decreasing elliptic dependence on relative normal reaction on the site of slipping according to the schedule, presented in Fig. 1, by formula

$$
\mu_{\text {trslip }}=\mu_{\text {rest }}-\sqrt{\left(\mu_{\text {rest }}-\mu_{s l}\right)^{2}-\left(\mu_{\text {rest }}-\mu_{s l}\right)^{2}\left(1-\delta_{R z s l i p}\right)^{2}},
$$

where $\mu_{\text {rest }}$ - coefficient of static friction of the contact area of the tire on seating in the absence of slipping of the wheel;

$\mu_{\text {slip }}$ - coefficient of sliding friction of the contact area of the tire at full slipping of the wheel.

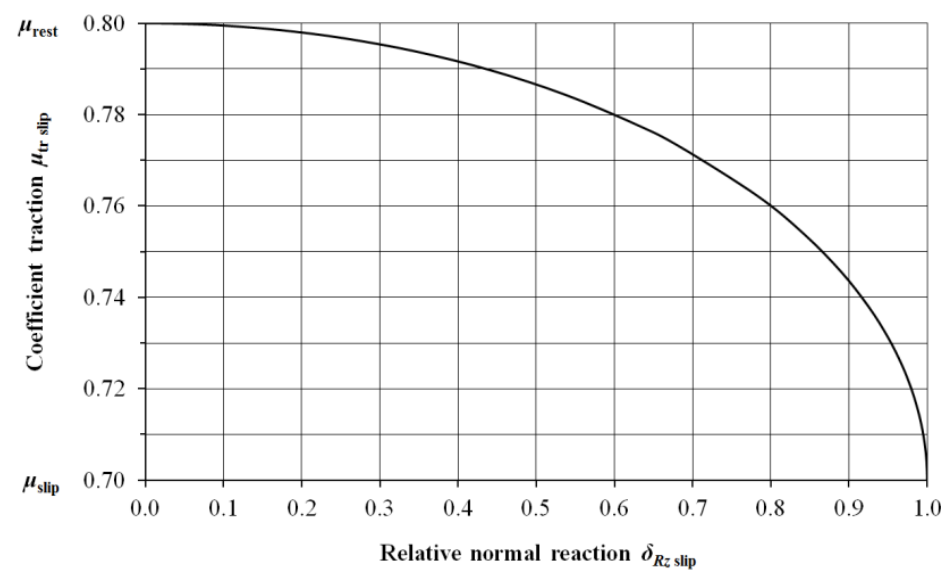

Fig. 1. Dependence of coefficient of traction $\boldsymbol{\mu}_{\mathrm{trslip}}$ on $\boldsymbol{\delta}_{\mathrm{Rz} \text { slip }}$

The maximum value of the dynamic coefficient of traction is equal to the coefficient of static friction of the contact area of the tire on seating in the absence of slipping of the wheel, and minimum - to the coefficient of sliding friction of the contact area at full slipping of the wheel.

The static coefficient of traction on the site of rest of the contact platform of the tire is determined by the increasing elliptic dependence on relative normal reaction on the site of rest, according to the schedule presented in Fig. 2, by formula

$$
\mu_{\text {trrest }}=\sqrt{\mu_{\text {rest }}^{2}-\mu_{\text {rest }}^{2} \delta_{\text {Rzrest }}^{2}},
$$

where $\delta_{R z r e s t}-$ relative normal reaction on the site of rest of the contact area of the tire.

The minimum value of the coefficient is equal to zero in the absence of slipping of the contact area of the tire, and the maximum value is equal to the coefficient of static friction of the contact area of the tire on seating at the time of transition to full slipping, when the last extreme rear element of the contact area still continues to be at rest.

The sum of relative normal reactions of the contact area of the tire on the site of rest and on the site of slipping is equal to the unit, that is

$$
\delta_{R s s l i p}+\delta_{R z r e s t}=1 .
$$


The coefficient of slipping of the wheel is defined by functional dependence on the coefficient of slipping of the contact area of the tire $\delta_{\text {slip }}$, the circle evolvent received on the basis of the polar equation [9].

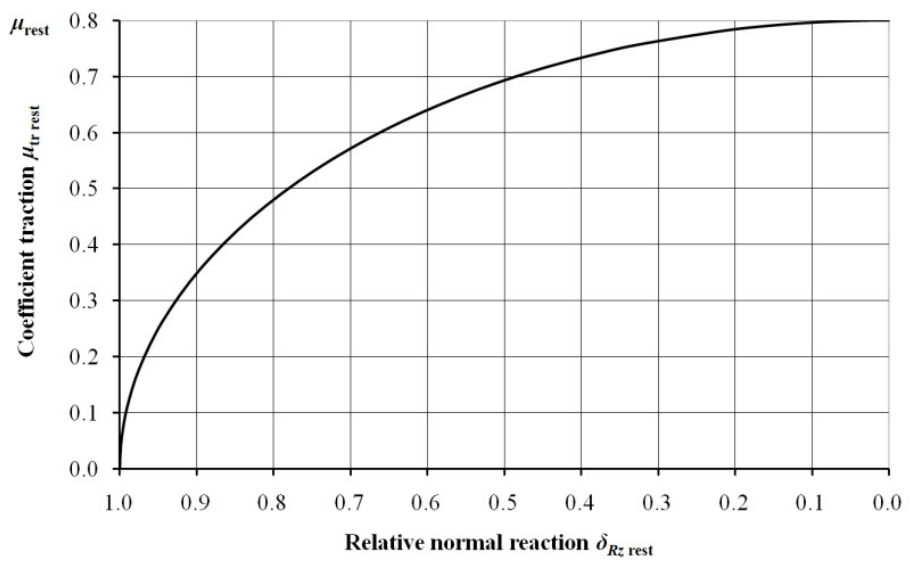

Fig. 2. Dependence of coefficient of traction $\boldsymbol{\mu}_{\text {tr rest }}$ on $\delta_{\text {Rz rest }}$

$$
\delta_{k}=\frac{\alpha_{k} \delta_{\text {slip }}}{\sqrt{4 \pi^{2}\left(1-\delta_{\text {slip }}\right)+\alpha_{k}^{2} \delta_{\text {slip }}}},
$$

where $\alpha_{k}$ - central angle of the contact area of the tire on seating, which is defined by the angle between the beams, which are coming from the center of the shaft of the wheel and passing through extreme rear and extreme lobby of the point of the contact area of the tire.

Inverse relation of the coefficient of slipping $\delta_{\text {slip }}$ of the contact area of the tire from the coefficient $\delta_{k}$ of slipping of the wheel is presented by expression

$$
\delta_{\text {slip }}=\frac{\left(\alpha_{k}^{2}-4 \pi^{2}\right) \delta_{k}^{2}+\sqrt{\left(16 \pi^{4}-8 \pi^{2} \alpha_{k}^{2}+\alpha_{k}^{4}\right) \delta_{k}^{2}+16 \pi^{2} \alpha_{k}^{2} \delta_{k}^{2}}}{2 \alpha_{k}^{2}} .
$$

Central angle $\alpha_{k}$ of the contact area of the tire on seating is possible to be determined by help of data from the technical characteristics of tires [11]. Basic data are the static radius $r_{s t}$ of the tires at standard wheel load and the length $l_{s c}$ of the circles of the tire rolling, which are defined according to the GOST ISO 11795-2004 "Tires of driving wheels of agricultural tractors. Method of measurement of length of circle of the tire rolling". For determination of the numerical value of the central angle $\alpha_{\mathrm{k}}$ it is necessary to solve the transcendental equation

$$
\alpha_{k}=2 \frac{r_{s t}}{r_{s c}} \operatorname{tg} \frac{\alpha_{k}}{2},
$$

where $r_{s c}$ - radius of the circle of the tire rolling determined by formula

$$
r_{s c}=\frac{l_{s c}}{2 \pi} \text {. }
$$

Rolling radius of the wheel in the free mode is identified with the radius of the circle of the tire rolling, that is

$$
r_{k f}=r_{s c} .
$$

Besides, an important estimated indicator of overall performance of the wheel is the tractive effort coefficient (specific longitudinal tractive effort), which is defined by the relation of longitudinal tractive effort of the wheel to vertical wheel load

$$
k_{R x}=R_{x} / G_{k} .
$$


For determination of the optimum value of the coefficient of slipping of the wheel at the maximum longitudinal tractive effort and at the maximum traction moment on the wheel it is necessary to define maximum of the function of weight ratio longitudinal tractive effort of $k_{R x}$ and the weight ratio traction moment of $k_{M t}$ on the wheel

$$
k_{R x}=\frac{R_{x}}{G_{k}} \rightarrow \max , k_{M t}=\frac{R_{x} r_{k}}{G_{k} r_{k f}} \rightarrow \max .
$$

Taking into account the structural components of expressions (1)-(8) the function of the weight ratio traction moment can be transformed to expression

$$
k_{M t}=\left[\mu_{\text {trrest }}-\left(5 \delta_{\text {slip }}^{2}-10 \delta_{\text {slip }}^{3}+10 \delta_{\text {slip }}^{4}-4 \delta_{\text {slip }}^{5}\right)\left(\mu_{\text {trrest }}-\mu_{\text {trslip }}\right)\right] \times\left(1-\delta_{k}\right) \rightarrow \max .
$$

Probe of functions (20) and (21) on extremum allows to find extreme and admissible ranges of the coefficient of slipping of wheels in the traction mode. At the known values of the vertical wheel load $G_{k}$ and rolling radius of the wheel in the free mode $r_{k f}$ parameters are calculated in the following order: 1) coefficient of slipping of the wheel $\delta_{k} ; 2$ ) coefficient of slipping of the contact area of the tire $\delta_{\text {slip }}$; 3) normal reaction on the site of slipping of the contact area of the tire $R_{z \text { slip }}$; 4) relative normal reaction on the site of slipping of the contact area of the tire $\delta_{R z s l i p}$; 5) relative normal reaction on the site of rest of the contact area of the tire $\delta_{R z \text { rest }} ; 6$ ) dynamic coefficient of traction of the contact area of the tire on the site of slipping $\mu_{t r ~ s i p}$; 7) static coefficient of clutch of the contact area of the tire on the site of rest $\mu_{t r}$ rest $; 8$ ) longitudinal jet force on the site of slipping of the contact area of the tire $R_{x s l i p}$; 9) longitudinal jet force on the site of rest of the contact area of the tire $R_{x}$ rest $; 10$ ) resultant longitudinal tractive effort $R_{x}$; 11) weight ratio longitudinal tractive effort $k_{R x} ; 12$ ) rolling radius of the wheel in the traction mode $\left.r_{k} ; 13\right)$ weight ratio traction moment $k_{M t}$.

\section{Results and discussion}

Graphic dependences of the weight ratio power parameters of the wheel on the coefficient of slipping of the wheel at variable values of the central angle of the contact area of the tire are presented in Fig. 3 and 4.

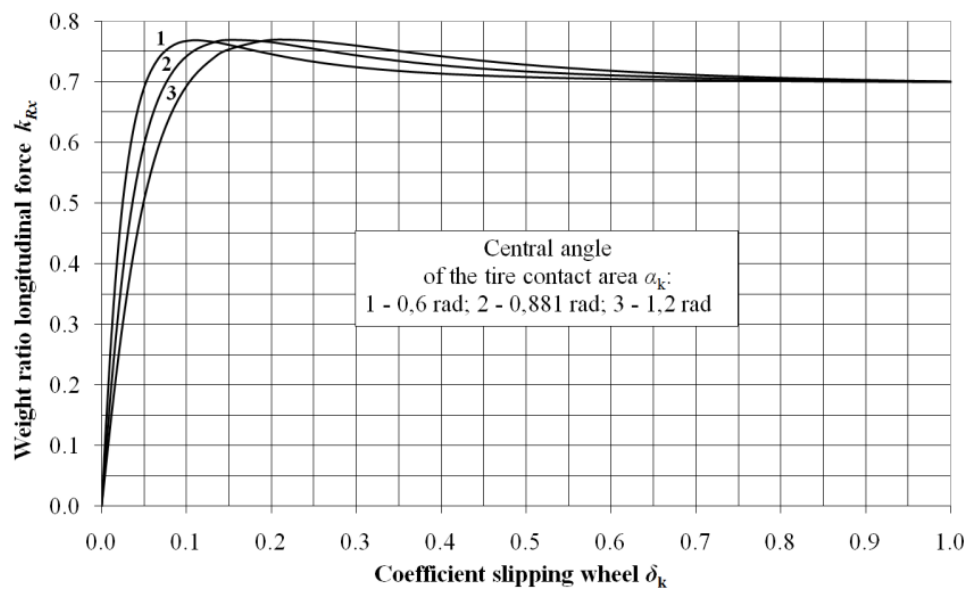

Fig. 3.Dependence of weight ratio longitudinal force $\boldsymbol{k}_{R x}$ on coefficient $\delta_{k}$ and angle $\alpha_{k}$

Graphic dependences are given for the model tire Goodyear OPTITRAC DT812 standard size 520/70R38, established on rear driving wheels of the tractor BELARUS 82.1 [14]: length of the circle of the tire rolling $l_{s c}=5258 \mathrm{~mm}$; static radius of the wheel at normal loading and internal pressure of air in the tire $r_{s t}=782 \mathrm{~mm}$; rolling radius of the wheel in the free mode $r_{k f}=837 \mathrm{~mm}$; central angle of the contact area of the tire on seating in variation $\alpha_{k}=0.6 ; 0.881 ; 1.2 \mathrm{rad}$; tire static friction coefficient on seating $\mu_{\text {rest }}=0.8$; tire sliding friction coefficient at full slipping of the wheel $\mu_{\text {slip }}=0.7$.

The analysis of the dependences given in Fig. 3 and 4 confirms that the invariance of the maximum value of the realized weight ratio longitudinal traction effort of $k_{R x}$ and reduction of the weight ratio traction moment of $k_{M t}$ in the process of increase in the central angle $\alpha_{\mathrm{k}}$ the contact area of 
the tire is natural at simultaneous increase in the corresponding extreme value of the coefficient $\delta_{k}$ slipping of the wheel.

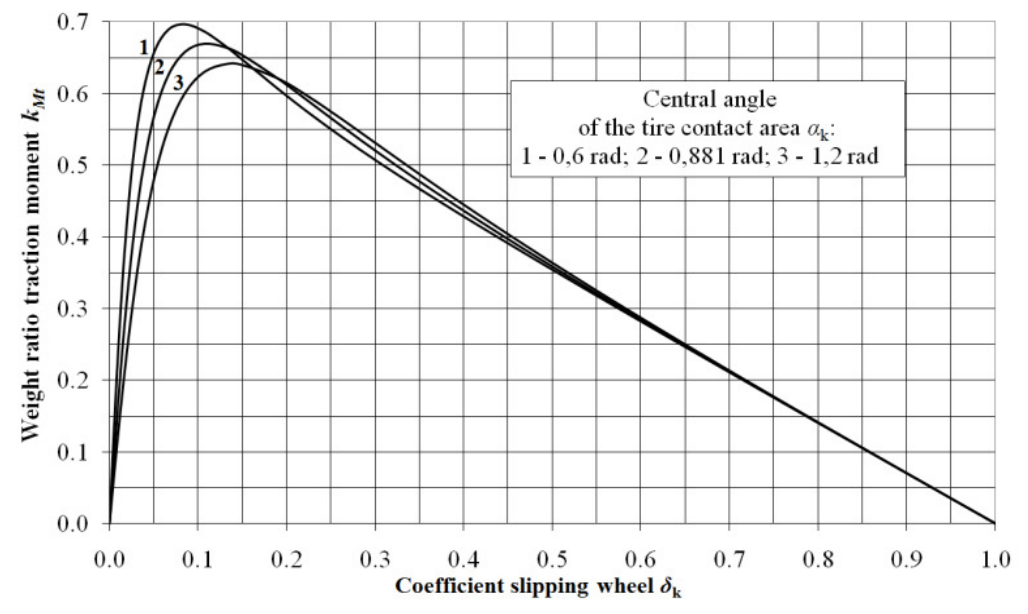

Fig. 4.Dependence of weight ratio traction moment $\boldsymbol{k}_{M t}$ on coefficient $\delta_{k}$ and angle $\alpha_{k}$

For the wheel and the tire with the mentioned parameters, for example, at $\alpha_{k}=0.881 \mathrm{rad}$ for standard operational wheel load, the maximum value of the weight ratio traction moment is $k_{M t}=0.669$ at the coefficient of slipping of the wheel $\delta_{k}=0.107$, the weight ratio traction force $k_{R x}=0.750$. It will well be coordinated with the data from other references, for example [1;2] and [15], in which it is established that the agricultural tractor most effectively works at the coefficient of slipping of driving wheels equal to $12-13 \%$ and 8-12\%, taking into account the criterion of minimum of specific energy consumption and maximum of traction efficiency. The maximum value of the weight ratio longitudinal force is $k_{R x}=0.769$ at the coefficient of slipping of the wheel $\delta_{k}=0.150$, the weight ratio traction moment $-k_{M t}=0.653$. Therefore, the value $\delta_{k}=0.150$ limits extremely the allowed range of the coefficient of slipping of the wheel that meets the operational requirements.

\section{Conclusions}

1. The presented results of analytical probes of specific power parameters and the coefficient of slipping of the driving wheel of the tractor are comparable to the data of other probes received taking into account various criteria at their calculation.

2. The results can find practical application at traction calculations of machine-tractor aggregates on the basis of wheel tractors and optimization of their operating characteristics, in particular, loads of wheels and air pressures in tires.

3. The technique of determination of the weight ratio power parameters and the coefficient of slipping of the driving wheel of the tractor is approved and is recommended for assessment of the efficiency and choice of rational traction modes of behavior and also at restriction of the allowed slipping in various service conditions caused by coupling properties of tires in interaction with seating.

\section{References}

[1] Самсонов В.А. Расчет номинальных значений основных показателей сельскохозяйственного трактора (Calculation of nominal values of the main indicators of agricultural tractor). Тракторы и сельхозмашины, 2016, No10, pp. 19-24. (In Russian).

[2] Самсонов В.А., Лачуга Ю.Ф. Расчет оптимальных значений мощности и энергонасыщенности сельскохозяйственного трактора (Calculation of optimal power and energy saturation of an agricultural tractor).Тракторы и сельхозмашины, 2017, № 7, pp. 25-31. (In Russian).

[3] Pacejka H. Tire and Vehicle Dynamics. 3rd Edition. Butterworth-Heinemann. Elsevier, 2012. 629 p.

[4] Wong J.Y. Theory of Ground Vehicles. 3rd Edition. Wiley-Interscience, 2001. 560 p.

[5] Rajamani R. Vehicle Dynamics and Control. Second Edition. Springer, 2012. 512 p. 
[6] Khaleghian S., Emami A., Taheri S. A technical survey on tire-road friction estimation / Friction, June 2017, Volume 5, Issue 2, pp 123-146. [online] [13.04.2019]. Available at: https://link.springer.com/content/pdf/10.1007 \%2Fs40544-017-0151-0.pdf.

[7] Jazar R.N. Vehicle Dynamics: Theory and Application. 2nd Edition. Springer, 2014. 1074 p.

[8] Popp K., Schiehlen W. Ground Vehicle Dynamics. Springer, 2010. 366 p.

[9] Годжаев 3.А., Русанов А.В., Ревенко В.Ю. Метод построения эпюр касательных напряжений в зоне контакта буксующего колеса с почвой. (The method of constructing the diagrams of tangential stresses in the contact zone of an axle wheel with soil). Тракторы и сельхозмашины, 2017, № 5, pp. 39-47. (In Russian).

[10] Balakina E.V., Zotov N.M., Fedin A.P. Azones of Static and Slip Friction in the Patch of Contact of a Vehicle Tire with Solid Bearing Surface. World Applied Sciences Journal, 2013, Vol. 27, No 4. pp. 428-431.

[11]Балакина Е.В. Расчет $\varphi$-S-диаграмм на основе обобщения результатов зарубежных экспериментов (The calculation of the $\varphi$-S-diagrams on the basis of generalization of the results of foreign experiments). Автомобильная промышленность, 2014, № 6, pp. 18-19. (In Russian).

[12] Романченко М.И. Кинематические параметры качения колеса в ведущем режиме. (Kinematic parameters of rotation of a wheel in a leading mode). Вестник ФГОУВПОМГАУ им. В.П. Горячкина, 2009, № 2 (33). pp. 46-49. (In Russian).

[13] Romanchenko M.I. Justification of the allowed coefficient of slipping of wheels of the tractor vehicle. Novi Sad, Serbia. Tractors and power machines, Vol. 19, № 2, Dec. 2014, pp. 47-52.

[14]Шиныдля тракторов, сельскохозяйственных машин и лесозаготовительной техники Goodyear OPTITRACDT812 (Tires for tractors, farm vehicles and the logging equipmentGoodyear OPTITRAC DT812) (In Russian). [online] [07.01.2019]. Available at: http://www.teh-center.ru/index.php?productID=1322.

[15] Janulevicius A.,Pupinis G., Juostas A. Mathematical description of tractor slippage. Engineering for rural development, Jelgava, 23.-25.05.2018, pp. 405-411. 